\title{
Diversity Networks: Networking for Equality?
}

\section{Marjolein Dennissen, Yvonne Benschop and Marieke van den Brink ${ }^{1}$}

Institute for Management Research, Radboud University, P.O. Box 9108, 6500 HK Nijmegen, The Netherlands, and ${ }^{1}$ Radboud Social and Cultural Science, Radboud University, P.O. Box 9102, 6500 HC Nijmegen, The

Netherlands

Corresponding author email: m.dennissen@fm.ru.nl

\begin{abstract}
In recent years, the use of diversity networks as diversity management instruments in organizations has increased tremendously. Diversity networks support the needs of employees with different social identities, such as women, ethnic minorities, LGBTs, disabled and young people. The aim of this study is to come to a better understanding of how diversity networks contribute to equality by examining how diversity network leaders discursively construct the value of their networks against the backdrop of discourses on diversity and equality. We conducted a multiple case study of five different diversity networks in a financial service organization in the Netherlands. Our results show that network leaders tend to construct the value of their networks primarily in terms of individual career development and community building, to prevent their members' isolation. However, they are much less articulate about removing the barriers to inclusion in the organization as a core value of their networks. We conclude that the value of diversity networks is limited when these networks only address the individual and group levels of equality and leave systemic inequalities at the organizational level unchallenged.
\end{abstract}

\section{Introduction}

Diversity networks are a widely popular practice in current organizations to promote organizational equality (Benschop et al., 2015; Kaplan, Sabin and Smaller-Swift, 2009). As part of the larger diversity management agenda, these in-company networks are initiated to inform, support and advance employees with historically marginalized social

We would like to express our gratitude to the two anonymous reviewers and to the associate editor, Professor Olga Epitropaki, for their valuable comments and support. Special thanks go to our respondents and to the members of the interdisciplinary research group Gender and Power in Politics and Management for their suggestions to improve previous versions of our text.

*A free Teaching and Learning Guide to accompany this article is available at: http://onlinelibrary.wiley.com/ journal/10.1111/(ISSN)1467-8551/homepage/teaching learning_guides.htm identities (Foldy, 2002). Hitherto, research has provided some insights into the value of diversity networks for women, ethnic minorities and lesbian, gay, bisexual and transgender (LGBT) employees. For instance, diversity networks are perceived to have a positive effect on members' career advancement (Cross and Armstrong, 2008; O’Neil, Hopkins and Sullivan, 2011), facilitate a safe space for members to share experiences (Friedman, 1996, 1999; Pini, Brown and Ryan, 2004) and provide possibilities to advise management about diversity and equality-related issues (Colgan and McKearney, 2012; Gremmen and Benschop, 2013).

Despite their valuable contribution to the field of diversity management research, these studies present several important limitations. First, the majority of these studies seem to make 'diversity' too easily 'doable' (Prasad and Mills, 1997, p. 11). Diversity networks have met scholarly critique for their lack of power to challenge organizations as they would have no choice but to follow the managerial agenda (Foldy, 2002). Yet, there is

(c) 2018 The Authors. British Journal of Management published by John Wiley \& Sons Ltd on behalf of British Academy of Management. Published by John Wiley \& Sons Ltd, 9600 Garsington Road, Oxford OX4 2DQ, UK and 350 Main Street, Malden, MA, 02148, USA.

This is an open access article under the terms of the Creative Commons Attribution-NonCommercial-NoDerivs License, which permits use and distribution in any medium, provided the original work is properly cited, the use is noncommercial and no modifications or adaptations are made. 
little dispute about the value of diversity networks as a popular diversity management instrument. Much of the literature emphasizes the beneficial effects for diversity and equality in organizations and ignores tensions, conflicts and contradictions (with Bierema, 2005; Colgan, 2016; Foldy, 2002 as notable exceptions). Managing diversity is powerladen, contextual and ambivalent (Ahmed and Swan, 2006; Prasad and Mills, 1997; Tatli, 2011), and accomplishing organizational equality by means of diversity networks is more complicated than simply creating a network (Bierema, 2005). Addressing diversity networks in a 'feel-good way' (Hoobler, 2005, p. 55) overlooks asymmetrical power relations that foster systemic inequalities in organizations.

Second, studies are ambiguous about whether diversity networks achieve their intended results (Bierema, 2005; Kalev, Dobbin and Kelly, 2006). Diversity networks possibly benefit both marginalized groups and the organization as a whole, but it remains unclear if and how networks fulfill this potential. Diversity network research presents a scattered field and the implications of diversity networks for organizational equality remain an understudied terrain. Hitherto, an overarching theoretical framework on the function of diversity networks as diversity management instrument is lacking. Hence, there is a need for better theoretical insights into the potential of diversity networks to diminish organizational inequalities.

To address these limitations, we turn to critical diversity studies (Lorbiecki and Jack, 2000; Oswick and Noon, 2014; Prasad and Mills, 1997; Zanoni et al., 2010) that focus specifically on inequalities in organizations and the underlying processes, practices and discourses that maintain and reproduce it. Taking into account inequalities and marginalized organizational voices, critical diversity studies provide 'unique and important ways to understand organizations and their [diversity, Eds] management' (Alvesson and Deetz, 2000, p. 10). A critical diversity perspective allows us to analyse the value of diversity networks for organizational equality as a key goal for diversity management that goes beyond numerical diversity.

In line with critical diversity studies, we study diversity networks as a vehicle for greater organizational equality, conceptualized as the absence of systematic disparities in power and control over goals, resources, behaviours, agendas, cultures and outcomes (Acker, 2006; Kärreman and Alvesson,
2009). The aim of this study is to gain a better understanding of how diversity networks contribute to equality by examining how diversity network board members discursively construct the value of their networks against the backdrop of discourses on diversity and equality. Capturing the board members' constructions of the value of their diversity networks demonstrates how they legitimize the existence and functioning of their networks in their organization. We provide a fine-grained analysis of the contradictory discursive practices and show whether and how the networks address organizational inequalities, and how their constructions vary across different networks. These insights will enable us to provide a more comprehensive understanding of how diversity networks help or hinder organizational equality.

We contribute to the theory and practice of diversity network studies in two ways. First, we show the ambiguities and contradictions in the legitimating discourses that simultaneously produce and counteract equality. This means that diversity networks sometimes tame diversity instead of changing the status quo. Second, drawing on theories from network studies, diversity studies and gender studies, we develop a threelevel framework to theorize the value of different diversity networks for equality in organizations. By doing so, we show that the contribution of diversity networks is limited when these networks only address the individual and group levels of equality and leave systemic inequalities at the organizational level unchallenged.

\section{Theoretical framework}

\section{Networks in organizations}

The popularity of diversity networks in organizations is based on the widespread idea that involvement in networks presents an important career management strategy. Ample studies have shown that successful networking is associated with positive career outcomes such as job opportunities, promotions, higher wages, influence and status (e.g. Borgatti and Foster, 2003; Granovetter, 1973; Kilduff and Brass, 2010; Mehra, Kilduff and Brass, 1998). Moreover, networks are considered to enhance and strengthen social ties, which increases satisfaction, social support and embeddedness, and lowers the risk of isolation (Bagilhole and Goode, 2001; Forret and Dougherty, 2004). As 
such, networks are seen as valuable on both a resource level (i.e. access to information, other networks and decision-makers) as well as a relational level (i.e. support, trust and solidarity) (Nahapiet and Ghoshal, 1998).

Although networks are overall seen as beneficial, studies also highlighted that networks can generate inequalities (Ibarra, 1997; Konrad, 2007; Rothstein, Burke and Bristor, 2001). For example, Rothstein, Burke and Bristor (2001) found that women have fewer links to senior managers in the organization, who were predominantly men. In addition, Konrad (2007) found that black women have limited access to informal networks. Likewise, Kalev, Dobbin and Kelly (2006) showed that black women and black men do not benefit from networks in the same way that white women do. Thus, networks can create inequalities in job opportunities, access to information, status and support when social groups such as women and ethnic minorities are excluded from white, male-dominated networks and cannot tap into the same resources, such as strategic network relations, powerful sponsors and higher-status connections (Burt, 1998; Forret and Dougherty, 2004; Ibarra, 1997; McDonald, 2011). Diversity networks were initiated to counteract these inequalities.

\section{Diversity networks in organizations}

Based on the beneficial effects of networks in general, diversity networks would present a strategy for advancing the positions of historically excluded groups within organizations (Foldy, 2002; Tomlinson, 1987). Emanating from the USA, the first diversity networks in organizations addressed women and ethnic minorities, aiming for their social inclusion and increasing their numerical representation in the higher organizational echelons (Friedman, 1996; Gremmen and Benschop, 2011; Pini, Brown and Ryan, 2004). Currently, different diversity networks exist for a much wider range of employee groups, focusing for instance on sexualities, disabilities, religion or age (Kaplan, Sabin and Smaller-Swift, 2009). The existent literature focuses mainly on women's networks, ethnic minority networks and LGBT networks. To our knowledge, there is no literature available on networks for disabled or young employees. ${ }^{1}$

\footnotetext{
${ }^{1}$ Even though the young do not constitute a marginalized group, networks for young employees are diversity net-
}

The dominant discourse about diversity networks lauds these networks for being an effective instrument in promoting organizational equality. Although organizations initiate diversity networks to manage their diverse workforce (Bierema, 2005; Kaplan, Sabin and Smaller-Swift, 2009), research has yielded ambiguous results. On the one hand, studies show that women's networks are effective in fostering a collective identity and decreasing feelings of isolation (Pini, Brown and Ryan, 2004), offering access to information and opportunities for upward career development (Cross and Armstrong, 2008) and enhancing members' visibility, leadership skills and confidence (O'Neil, Hopkins and Sullivan, 2011). Likewise, ethnic minority networks can have a positive effect on members' perceived career advancement (Friedman, Kane and Cornfield, 1998), reduced turnover intentions and social embeddedness (Friedman and Craig, 2004; Friedman and Holtom, 2002), and provide a safe space without the need to conform to the dominant organizational culture (Friedman, 1996, 1999). On the other hand, studies showed counterproductive effects (Kalev, Dobbin and Kelly, 2006). For example, research refutes that ethnic minority networks would provide members with much opportunity to diminish inequalities (Friedman, 1996). Also, women's networks are often the object of ridicule (Gremmen and Benschop, 2011; Vinnicombe, Singh and Kumra, 2004), affecting their legitimacy and resulting in women's reluctance to participate actively (Bierema, 2005). In order to elaborate on these contrasting findings, we briefly turn to theories on organizational equality from the field of gender studies.

\section{Paradigms of diversity and equality in organizations}

As for most diversity management practices, inequality theories lie at the root of the implementation of diversity networks (Kalev, Dobbin and Kelly, 2006). Theoretical insights and conceptualizations from gender equality research have largely influenced and shaped the theory and practice of in/equality at work and in organizations (Benschop, 2006). Organizational equality is a difficult and challenging concept; it is not formulaic, there is no identifiable endpoint and

works in the sense that they are organized on the social category of age. 
every organization is unique (Ely and Meyerson, 2000b; Meyerson and Fletcher, 2000). Kolb et al. (1998) introduced a framework to summarize how organizations possibly approach organizational (gender) equality. In this framework, they distinguish between traditional approaches geared towards minority employees to get them on a par with majority employees, and non-traditional approaches that focus on changing organizational processes, work practices and everyday interactions that contribute to the (re)production of systemic inequalities in organizations (Acker, 2006; Ely and Meyerson, 2000a; Zanoni et al., 2010).

Diversity networks are predominantly seen as an instrument to increase the number of historically marginalized employees, focusing on their numerical representation in management ranks. Diversity networks meet scholarly critique for their emphasis on 'fixing' organizational minorities. Although this may help individual minority employees in their career advancement, organizational processes (re)producing systemic inequalities go unchallenged (Benschop et al., 2015; Meyerson and Kolb, 2000; Zanoni et al., 2010). Some authors argue that diversity networks should focus exclusively on supporting and connecting their members, and not on broader organizational changes (cf. Friedman, 1996). However, other authors argue that diversity networks can play a role in increasing equality (Briscoe and Safford, 2008, 2010; Githens and Aragon, 2009; McFadden and Crowley-Henry, 2017). For example, Colgan and McKearney (2012) show that an LGBT network can become an 'agency for change' by shaping and driving the organizational sexual orientation equality agenda. Bell et al. (2011) propose that LGBT networks create opportunities to challenge the organization by providing LGBT employees with voice and visibility. Similarly, Meyerson and Fletcher (2000) propose that groups of employees can meet and discuss common problems and underlying factors, which 'opens up the possibility of change' (p. 135), not only for individual employees, but also for the overall organization.

To understand the value of diversity networks for organizational equality, we develop a theoretical framework that can take into account the contribution of diversity networks to organizational equality on multiple levels. In the following section, we present such a framework.

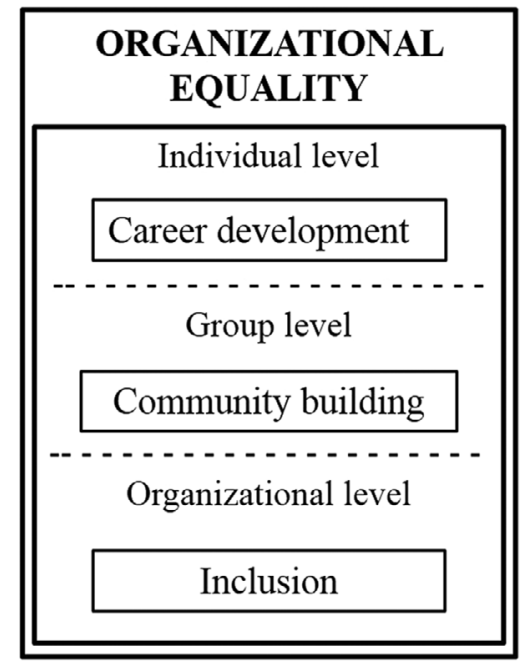

Figure 1. Three-level framework of organizational equality

\section{Towards a framework of diversity networks and equality}

Based on theories from network studies, diversity studies and gender studies, we distinguish networks' effects on equality on three main levels: network members individually, members as a group and the organization as a whole. We conceptualize equality effects at the individual level as the contribution of networks to individual career development. Equality effects at the group level are conceptualized as the contribution of networks to community building. Networks can bring their members together to reduce their isolation in majority groups: members can connect, share experiences and build social support and cohesion between them (Friedman, 1996, 1999; Colgan and McKearney, 2012). Equality at the organization level is conceptualized as a contribution of networks to inclusion, that is, the full participation of all employees in all formal and informal organization processes (Mor Barak, 2015). Figure 1 shows our three-level framework of organizational equality.

Our literature review shows that it is not self-evident that diversity networks contribute to equality on all levels: some networks are more career-oriented, while others aim to combat group isolation, or focus on changing policies. To gain a better understanding of diversity networks' contributions to equality, we now turn to the key figures of diversity networks, the network board members. Diversity network board members play a crucial 
Table 1. Composition of the workforce in Finance

\begin{tabular}{lc}
\hline Group & Percentage \\
\hline Women (overall) & $48.0 \%$ \\
Women (top) & $30.0 \%$ \\
Ethnic minorities & $16.0 \%$ \\
LGBTs & $6.0 \%$ \\
Disabled employees & $1.4 \%$ \\
Age 20-29 & $7.5 \%$ \\
Age 30-34 & $14.5 \%$ \\
\hline
\end{tabular}

Source: Intra-organizational magazine (2014) about diversity.

role in making strategic network decisions, defining the network goals and organizing network activities for members. Our theoretical framework provides us with the conceptual tools to analyse the goals and values board members construct for their diversity networks in relation to the different levels of organizational equality.

\section{Methodology}

To examine how diversity network board members construct the value of their diversity networks discursively, we use a qualitative research strategy. We conducted a multiple case study of five different diversity networks within a financial service organization in the Netherlands (Finance). A multiple case study supports the analysis of complex and little-understood phenomena within real-life, organizational contexts (Eisenhardt and Graebner, 2007; Yin, 2009). A multiple case study allows for multiple methods of data collection, which can be compared and contrasted in order to identify ambiguities and contradictions in the data. This provides in-depth insights into different networks, including networks that have not been studied before. We selected this organization as it accommodates different diversity networks: a women's network, an ethnic minority network, an LGBT network, a network for disabled employees and a network for young employees (aged 18-35), which allows us to make a comparison of these networks.

\section{Case description and data collection}

We collected our data in an organization located in a large Dutch city, employing 20,000 people. In Table 1, an overview is presented of the composition of the workforce in terms of diversity.

This paper is based on 30 in-depth interviews with former and current diversity network board members ( 18 women and 12 men, aged between 26 and 59). An overview of the respondents can be found in Appendix A1. We selected network board members for two reasons: as board members they communicate the value of their diversity networks both to potential members and to the organization for resources and support; and they are responsible for the actions and activities of their diversity networks. As such, the board members are the de facto leaders of their networks.

The interviews were conducted by the first author and took place at a location agreed with the interviewee, usually at the interviewee's workplace. The interviews were conducted in Dutch, lasted between 45 minutes and 2 hours, were taperecorded and transcribed verbatim. The interviews were guided by a semi-structured interview guide (Appendix A2), with questions about how and why the networks were initiated, the networks' structure, membership, goals and activities, and organizational support. In addition, we collected and analysed the annual plans and newsletters of the diversity networks. These documents provided information about formal mission statements, objectives and activities, offering additional insight into how diversity network board members legitimize their networks to gain support and budget from the organization.

The quotes in this paper are translations of the original Dutch interview excerpts. We have stayed as close as possible to the original expressions and idiom. To secure anonymity and confidentiality, we have anonymized our respondents using fictitious names.

\section{Data analysis}

Our data analysis was an iterative process of going back and forth between the literature and our empirical material. We used the qualitative software package Atlas-ti to systemize and code our empirical material. We first coded our data in terms of content, using codes derived from the interview guide (Silverman, 2006), such as goals, activities, support and legitimation. This resulted in an overview of the goals, structure and activities of each network. In a second step, we compared these findings over the networks and reread the material, searching for how interviewees talked about the value of their networks. In the following section we present a selection of excerpts, Appendix A3 provides additional data. 
To further analyse these excerpts, we used discourse analysis delving deeper into what was said, how it was said, what was not said and the patterns of variation within the texts (Potter and Wetherell, 1994). Discourse analysis provided us with an entrance into the board members' 'dialogical struggle(s)' (Phillips and Hardy, 2002, p.25) that represent a two-way process: diversity network board members can either shape or be shaped by organizational, or broader societal, discourses representing familiar combinations of arguments and characterizations about equality and diversity in the workplace. We question which discourses feature in board members' constructions of the value of their networks and how interviewees' discursive constructions relate to a broader set of discursive practices around diversity and equality. Comparing the discursive constructions of the value of diversity networks across the different networks sheds light on how equality and inequality can either be challenged or reproduced.

\section{Findings}

For every diversity network, we explore how board members frame their goals and the activities they organize in order to realize these goals. We analyse different discourses that the board members draw on in their constructions of the value of their networks. An overview of the main characteristics of the different diversity networks can be found in Appendix A4.

\section{Women's network}

The women's network is organized explicitly for women in middle-management positions. According to the network's annual plan, the network is an 'informal network for ambitious women'. The board members primarily construct the notion of gender equality as numerical, aiming for more women in higher managerial positions. For this purpose, the network wants to support the career development of what they refer to as 'ambitious women'.

In order to facilitate women's career advancement, the board members organize several events and activities, such as a mentoring programme, round-table sessions and an annual event in cooperation with women in senior management positions. The main thread throughout these events is to provide members with the necessary tools for career advancement and professional empowerment. The board members emphasize 'professional' activities and assert that women themselves are responsible for their own career:

We have to stop whining about the glass ceiling. And tut-tut, we are so pitiable. [...] You can do a lot yourself. You can make it open to discussion, you can make it visible, you know. (Kate)

Board member Kate takes issue with the concept of the 'glass ceiling'. Instead of addressing organizational barriers, she states that women are not 'pitiable' but agentic. We distinguish a discourse of individual career responsibility which frames career development as a choice and constructs women as responsible for their career advancement by learning the rules of the game (see Appendix A3 for more illustrative quotes). The board members adopt hegemonic male models of success and networking:

You really want to apply for [a higher managerial position] because you want to grow, then you have to start thinking about how to put that in your network: call out what you can do. Men do that too. (Betty)

According to Betty, women have to 'really know what [they] want, and what [they] can do' if they want to further their careers in the way men do. In line with the 'equip the women' approach (Meyerson and Kolb, 2000), women are the ones who should assimilate and become as assertive, political and strategic as men if they want to be successful. With their activities, the women's network strives to empower their members professionally and enable them to follow the male models of career success.

Although the main focus of the board members is on individual women, they argue that it is important to involve men in their activities.

\footnotetext{
We involve men, absolutely, absolutely. [...] I am not saying that it starts with that, but it is a combination. The women have to work on it themselves, we [women] have to really do something instead of whining. And second, there are the men, who have to be aware of what they are doing. That they indeed hire a lookalike. (Kate)
}

As such, Kate does not focus solely on the empowerment of individual women, but also on awareness among men. She questions the behaviour of men, for instance in recruitment and selection 
processes. By involving men, she wants to raise awareness that male managers tend to hire 'lookalikes'. The board members believe men to be instrumental in bringing about change. Individual men need to be 'equipped' too, but men need a different kind of intervention geared to awareness of their hiring preferences, not the behavioural assimilation required of women.

Drawing on a discourse of individual career responsibility, the board members highlight the empowerment of individual women. This discourse corresponds to 'equip the woman' or 'liberal individualism' (Meyerson and Kolb 2000, p. 560). Although the board members do attempt to involve men and to raise awareness about recruitment and selection processes, the male models of career success and networking are never challenged but taken for granted as the standard for all employees.

\section{Ethnic minority network}

The ethnic minority network started as an interpersonal network of one employee with an ethnic minority background and has gradually developed into an official employee network. There are different, overlapping goals mentioned by various board members during the interviews and formulated in the network's annual plan. The overarching goal of this network is to connect employees throughout the organization. This entails both connections among employees with an ethnic minority background as well as between all employees, regardless of their background. We distinguish several subgoals: career development, for employees to 'feel at home within [the organization]', and to increase visbility and create awareness for ethnic diversity.

First, the career development of employees with an ethnic minority background stagnates at middle-management positions. To support the career development of members, the network organizes discussions, workshops and professional training sessions. For example, training about body language, where participants learn how to 'sell' themselves. This emphasizes individual responsibility for one's career. 'Feeling at home' is a second sub-goal. One of the board members explains that he had to 'turn some switches' in his behaviour to fit in when he just started to work in Finance. He therefore considers it important that ethnic minority employees have to 'turn as little switches' as possible to feel at home within the organization. For employees to feel at home and to facilitate the exchange of experiences, the network organizes monthly drinks. A third subgoal is to increase visibility and create awareness of ethnic diversity through an ongoing dialogue between members and senior management. The network wants to serve as a 'collective voice' to influence the agenda of the board of directors on diversity-related matters. The network organizes regular lunches and drinks for network members, managers and members of the board of directors.

We note that the board members emphasize the importance of awareness, calling attention to ethnic diversity and the struggles ethnic minority employees may encounter. Yet, in our interviews we observe ambivalence towards being visible as a network that spotlights ethnic diversity:

We do not want to give the impression that it is only for foreigners or something... The impression is just, we want to bond and connect, so then you want to include everybody. But that is a difficult task. (Hassan)

It sounds a bit contradictory, but you have ... I think you need it on the long term to show that actually you just belong to the [organization]. [...] To show that it is just something very normal. [...] And what is needed not to have it on the map any more, is to first put it on the map. (Glenn)

Hassan states explicitly that the network should not become, or be labelled, a network exclusively for ethnic minorities. Glenn voices similar feelings when he presents the ethnic minority network as a means to an end, the end being belongingness. Employees with a culturally diverse background are not different from any other employee, they are 'normal'. Glenn constructs 'equality' in the sense of 'sameness', avoiding any reference to inequality. This is 'a bit contradictory', as he also notes himself, because the network is legitimate exactly because of its focus on ethnic diversity. On the one hand, the board members state that it is important to increase the visibility of ethnic diversity, so that ethnic minority employees fit in without the need to assimilate. On the other hand, ethnic diversity should be 'normal'. Increasing the importance of ethnic diversity implicates more visibility of ethnic diversity, but that goes against the wishes of the board members for belongingness and blending in with the majority. In doing so, they are losing difference for equality. 
We see that board members invoke discourses of belongingness and visibility, in line with what Ghorashi and Sabelis (2013, p. 79) call 'a struggle in relation to sameness and difference'. This struggle is affected by a larger societal discourse on ethnic minorities, in which ethnic minorities are constructed as a deviation from the norm, and therefore as lacking (Ghorashi and Sabelis, 2013; Siebers, 2010). This is illustrated by existing tensions between the network and potential members, especially those in high positions who do not want to identify with, or be labelled, 'culturally diverse' as they link it to disadvantage and inequality. The board members believe the ethnic minority network is a temporary necessity to change the organization, yet they are reluctant to emphasize ethnic diversity too much, in fear of stigmatization and disadvantage. As such, differences are dismissed and the prevailing norms remain unchallenged.

\section{LGBT network}

The LGBT network was initiated by LGBT employees within the organization. Following an initiative to organize informal drinks, the network was formalized into an official diversity network. In our interviews, the board members mention two main goals. First, to support and advance the visibility of homosexuality, tolerance and acceptance of LGBT employees. According to the board members, LGBT employees who are 'out' would perform better at work compared with LGBT employees who hide their homosexuality. Second, the board members wanted to create a safe space where LGBT employees can 'feel at home'.

In order to advance the visibility of homosexuality and provide a safe space, the LGBT network organizes 'feel-good activities', mainly seminars with drinks afterwards. Network members are encouraged to bring a straight colleague to activities. Reaching out rather than withdrawing among network members is seen as facilitating the visibility of the network and of homosexuality in the organization. Instigated by the LGBT network, the organization also participated in the national Gay Pride Parade.

Although the board members want to advance the visibility of homosexuality throughout the organization, they are ambiguous about the kind of visibility:

The most important is that we... uh... advance the visibility of homosexuality. And with that I do not mean that we... uh... have to parade through the building like Gerard Joling. [...] That is not the visibility that I mean. That visibility can be there as well, but in general it is just ... uh ... that it is normal. So to speak, eh. That it, uh... so then you have a Gerard Joling, but there are also ... uh ... types like me, who are not immediately recognizable when you are straight, so to speak. It is about allowing the visibility in all its variety. (Anna)

In this excerpt, we observe a discourse of visibility, as Anna wants homosexuality to be visible, yet she is ambivalent about the type of visibility. Reference is made to the Dutch singer Gerard Joling, who is open about his homosexuality. Although this open type of homosexuality should be acceptable as well, and Anna refers to visibility in various ways, she speaks of 'normal' in reference to a homosexuality that is almost invisible, at least to straight eyes. In line with Anna, other board members are also careful not to confirm gay stereotypes. For example, about their participation in the national Gay Pride Parade, a board member states that 'it had to look professional', not 'too much nudity' and to 'make a statement that we are just normal people'. Another board member wants to challenge the stereotypical perception of 'partying gays $[\ldots]$ in pink underwear' by exemplifying that LGBTs are 'just employees and professional' (see also Appendix A3). As such, a stereotypical gay image is constructed as out of line with the professionalism of the organization:

\begin{abstract}
It is there but... it is no part of the work. You are just a good professional and, oh yes, gay, but that is not relevant to your work, to your position, to your performance $[\ldots]$ the best thing is that it is no explicit part of my ... how people evaluate me as professional. And it has to be like that. Also that flamboyant young man is not evaluated on the fact that he is flamboyant, he is evaluated on how he does his job. (Anna)
\end{abstract}

In this quote, Anna explicitly separates sexuality from professionalism, arguing that being gay is irrelevant for work performance and, in keeping with meritocracy, should not matter in professional assessment. As such, she draws on a discourse of professionalism that is supposed to be identity-blind. Board members assert that homosexuality should be considered as normal as heterosexuality, and LGBT employees are 'just normal people', invoking a discourse of 
normalization; a distinction is made between 'normal, invisible types' and 'flamboyant stereotypes'. This distinction could possibly create a 'hierarchy between honorable and unrespectable homosexuals' (Gusmano, 2010, p. 36). Moreover, openly claiming to be different from 'flamboyant' types presents a commitment and alignment to the heteronormative structure of the organization, where 'practices and institutions legitimatize and privilege heterosexuality' (Gusmano, 2010, p. 33).

Thus, we observe tensions and contradictions in the representation of the LGBT network as an instrument for the visibility and inclusion of homosexuality in the organization. On the one hand, in an organization where sexuality used to be rendered invisible and heterosexuality is considered the norm, the existence of an LGBT network calls into question taken-for-granted notions about sexuality. On the other hand, the privileging of the 'normal, professional gay type' and its contrast to the 'flamboyant homosexual' renders homosexuality invisible again, and implies compliance to the organization's heteronormative order.

\section{Disability network}

The disability network was initated by two employees with a disability. Being the youngest network in the organization, we note that the goals are not yet crystallized. Different, overlapping network goals are formulated in the network's development plan, in official network newsletters and by the board members themselves. We distill three core goals. First, the network aims to create visibility and awareness of disability in the organization. Second, the network provides a space of support for disabled employees. Third, the network aims to support and advise the organization by becoming a unit of expertise on disability-related issues.

The first goal is creating more visibility and awareness of the capabilities of disabled employees. Increasing visibility entails that the board members make sure that members of the network are involved in organizational events, such as including disability in organizational sports tournaments. However, the board members of the disability network are careful not to emphasize a particular visibility:

Naturally, [the network] stands for ability. Often people think about disability as lacking competency or lacking knowledge or lacking skills. What [the net- work] somewhat stands for is that is should not become a separate network for disabled but it has to be a network that has a connecting factor within [the organization]. (Tim)

This quote illustrates how board member Tim calls attention to the 'abilities' of disabled employees. Drawing on a discourse of ability and empowerment, Tim endeavours to stress the strengths and qualities of disabled people instead of highlighting their deficiencies. Therefore, the network is open to both disabled and able-bodied employees. The board members attempt to prevent stigmatization by arguing 'that [the network] is not a club of deficient people'. Moreover, by focusing on positive, humorous and playful actions, such as taking part in assault courses, they want to emphasize the capabilities of disabled employees.

The second goal is providing support for disabled employees, by offering a space where disabled employees can meet and discuss their struggles and experiences. Activities are, for example, open coffee hours and workshops about balancing energy and self-promotion.

The third goal is to support and advise the organization about disability-related issues. The network aims to become a unit of expertise, stimulating learning and development for their members and the organization. This is linked to the open membership of the network and in particular the involvement of managers. The board members explain that the involvement of managers is important because they are responsible for hiring, evaluating and including disabled employees. The following quote illustrates that board members criticize managers' mindsets about career development:

Look, if I came to work for somebody else and I am going to say, I want to work 16 hours divided over three days. Well, I think that HR will look rather strange if I am going to say that. Because they do not have that mindset. And especially a knowledgeintensive organization, so career, career, career. But you do not have to work 60 hours to make a career. That is also such a mindset that people have in their heads $[. .$.$] the manager and HR too. (Sarah)$

Sarah invokes a discourse of possibilities and organizational change by arguing that employees with a disability are able to have a career as well, if the narrow notion of a career changes. She calls for organizational changes in both mindset 
and organizational practices in order to include employees with disabilities as full organizational members.

Board members of the disability network call for an adaptation of the organization to accomodate the needs of the disabled employees who are literally not able to adapt themselves to the organization. However, their emphasis on mainly positive, uncritical interventions, the discourses of ability, empowerment, possibilities and change conveys an impression of a naïve positivity that resembles the early happy diversity discourses (cf. Prasad and Mills, 1997).

\section{Young employee network}

The young employee network was initiated by several young employees in the organization. With 1,300 members, it is the largest network of the organization. According to their annual plan, the goals of the young employee network are threefold. First, they want to bring young employees throughout the organization together for social activities, personal development and inspiration. Second, the young employee network wants to 'build bridges', meaning building relationships within the organization as well as between their own organization and other organizations. And third, the young employee network wants to 'contribute to the development of the [organization] and its image'.

Although these three goals are the formalized goals on paper, the network board members highlight that their 'core business' is socializing:

We just think it is cosy to get together for drinks and to learn from each other, to hear what everybody is doing. (Jenny)

We are an informal network, where you get to know each other by being there and have a beer together and attend an activity. That is how we come to the fore. (Michael)

These and the illustrative quotes in Appendix A3 show that board members use terms such as 'cosy', 'informal' and 'having a beer' to describe the essence of their network. Drawing on a discourse of socializing, the network is presented as a place where it is just nice to meet, have drinks and talk to other young people. Organized social activities are, for example, monthly drinks, a gala, a bowling event and a ski or sailing trip. These activities are not paid for by the network, but require an individual contribution.

According to the initiators of the network, young employees used to feel like the 'lowest servants'. They established the young employee network to change the organization, because the ideas of the 'new generation' about leadership differed from the 'grey' management. Today, young employees are regarded as talented employees who 'determine the future of [the organization]' (company website, 2014). The network is invited by top management to represent the point of view of the young employees, and they are involved in recruitment activities. Moreover, the network's organizational problem-solving committee advises the board of directors.

We observe that the status of young employees in the organization has changed over time, from the 'lowest servants' without power to 'ambitious talents' valuable for the future of the organization. Where young employees were once regarded as 'others', they are now included. As such, we argue that the young employee network is co-opted into the organization. This can be related to a broader organizational, and possibly societal, shift in discourse about young employees. We label this as the discourse of the glorification of the young. Within this discourse, young employees are considered to be young professionals and unique selling points, valuable in making a contribution to organizational performance (cf. Kelan, 2014). Involvement of young employees in critical organizational processes such as decision-making is not a matter of acceptance of diversity, but a token of their self-evident importance to the organization.

Compared to the other diversity networks, the young employee network is less restricted due to the taken-for-granted status of young employees in the organization. The power that is inherent to this status provides the board members with the opportunity to draw on a discourse of socializing. This contrasts with other diversity networks that have to engage in more professionalism-related discourses to legitimate their existence. However, the young employee network needs the discourse of the glorification of the young, that is directed towards the organization, in order to be able to uphold a discourse of socializing, that is directed towards the network's (potential) members. 


\section{Discussion and conclusion}

The aim of this study was to gain a better understanding of how diversity networks contribute to equality by examining how diversity network leaders discursively construct the value of their networks against the backdrop of discourses on diversity and equality. Thus far, the implications of diversity networks for organizational equality remained an understudied terrain. Tensions, conflicts and contradictions are overlooked, and an overaching theoretical framework on the function of diversity networks in diversity management is hitherto lacking. Analysing five different diversity networks with a critical diversity perspective, we fill the gap in the literature and contribute to the theory on diversity networks in two ways. First, we identified the discourses by which network board members legitimize the existence and functioning of their networks. This allowed us to uncover the tensions and dilemmas network board members are struggling with. Second, by further developing the framework on levels of equality, we theorize the value of diversity networks for equality in organizations. Our empirical study of five diversity networks has helped us to further elaborate the framework. Analysing the ambiguities and contradictions in the legitimating discourses, we show when and how diversity networks simultaneously produce and counteract equality on the individual, group and organizational level. We conclude our paper with theoretical and practical implications.

\section{Individual level: individual career responsibility}

First, in line with the literature (Bierema, 2005; Vinnicombe, Singh and Kumra, 2004), our findings show that network leaders see diversity networks as valuable for the career advancement of their members. Invoking a discourse of individual career responsibility, they emphasize that networks offer members useful tools for their careers. We have seen how the board members of the women's network predominantly construct the value of their network along these lines, as they see the network as a way to stimulate ambitious women to take responsibility for their professional career success. The ethnic minority network, and the LGBT network, also refer to career development for their members, but they construct this in terms of the structural and cultural barriers that impede the upward mobility of members of these networks, not so much as individual responsibilities. Yet, we observed ambiguity in the struggle of the board members of the ethnic minority network and the LGBT network with the discourse of professionalism. They want to stretch the meaning to normalize the professionalism of culturally and sexually diverse employees, but do so without critically questioning the underlying white and heteronormative conceptions of that professionalism (Bell et al., 2011). In contrast, the board members of the disability network emphasize the responsibility of the organization to change the notion of career to incorporate a wider array of work hours and work practices. The disability network strives for individual network members with disabilities to change or develop the organization, whereas it is the other way around for the women's network that seems to accept the organization and strives to change or develop the women. The emphasis on individual responsibility limits the contribution to equality and the individual level of equality becomes problematic when discourses of professionalism and individual choice prevail, without problematizing the gendered, classed and racialized connotations of 'career'.

\section{Group level: visibility and normalization}

The second level of equality is the group level. Here the contribution of diversity networks lies in community building between employees with similar social identities. When networks bring their members together so that they can connect (Friedman, 1996, 1999), share experiences and build social support and cohesion between them without having to conform to the majority culture (Colgan and McKearney, 2012), we see the contribution to equality at the group level. Our findings show how community building is particularly valued by the board members of the ethnic minority network, the LGBT network and the disability network, as their members may be isolated in work environments dominated by white, heterosexual and able-bodied colleagues. Yet, we observe that network leaders fear isolation when they are perceived as exclusive communities for ethnic minority, LGBT or disabled employees only. This reveals a tension between the discourse of visibility that the networks want to claim for their members and their discourses of normalization of their membership. Board members feel the need to increase the visibility of ethnic diversity, 
sexual diversity or disability in the organization, but fear the visibility of difference constructed as stigma, inequality and disadvantage at the same time. For example, the ethnic minority network does not want to give 'the impression that it is only for foreigners', and the LGBT network are cautious not to confirm stereotypes of 'gays in pink underwear'. Young employees, on the other hand, are not a traditional category of diversity and they are not 'othered' and marginalized like women, ethnic minorities, LGBTs and disabled employees. The discourses of the young employee network do not construct a young age as a dimension of inequality. This is reflected in the discursive celebration of the young as the future glory of the organization, that is unparalleled by any other diversity network. For the other networks, their minority status is obvious (Kelan, 2014) and, to escape the disadvantages of this minority status and facilitate a wider belongingness to the organization, network board members include supportive majority members. Opening up membership implies a more legitimate position for these networks in the organization and serves to de-emphasize the relevance of difference, toning it down to something more palatable to the wider organization (Nkomo and Hoobler, 2014). Simultaneously, the contribution of the networks to group-level equality is counteracted, when conformation to the majority culture prevails over challenging the lower status of minorities.

\section{Organizational level: inclusion, abilities and possibilities}

The third and last level of equality is the organizational level. We argued that the contribution of diversity networks at this level pertains to inclusion (i.e. the removal of obstacles to the full participation and contribution of employees to all formal and informal processes in the organization) (Mor Barak, 2015; Roberson, 2006). Inclusive organizations give all employees a voice, a sense of belonging, access to information, have them take part in decision-making, value their competencies and have them express multiple identities at work (Janssens and Zanoni, 2014; Mor Barak and Cherin, 1998). Our findings show that the board members of the disability network are the most vocal about inclusion as a value of their network. Drawing on a discourse of ability and possibilities, they challenge restrictive work practices and the narrow notion of a career. They construct their network as a center of expertise on disability issues, providing the organization with opportunities to learn how disabled people are able to contribute, focusing on strengths and qualities instead of deficiencies, and showing how the organization should adapt to disabled people rather than the other way around. Our analysis shows how the discourse of normalization also refers to inclusion: by stressing that it should be normal for their members to be hired and do their work, the board members of the ethnic minority network, the LGBT network and the disability network all see their networks as contributing to the inclusion of their social groups. Yet, as indicated by the tensions around visibility, the network board members of the ethnic minority network and the LGBT network seem to restrict inclusion to belongingness only and shy away from too strong claims to the difference and uniqueness of their members. Only when networks also address difference and the unique contributions of their members, and foster their sense of belongingness to the organization (Shore et al., 2011), can diversity networks contribute to inclusion on the organizational level.

We conclude that the presentation of diversity networks as valuable instruments for equality can only be partially supported by this study of five different diversity networks in a Dutch financial service organization. Our findings show that diversity network board members tend to construct the value of their networks primarily in terms of individual career responsibility and community building to prevent their members' isolation. While these represent the individual and group levels of equality and are valuable for equality as such, the organizational level of inclusion remains underplayed. This has profound implications for the contribution that diversity networks can possibly make to equality. When systemic inequalities in organizations go unchallenged, and no calls for substantial change in the organizational processes and practices (re)producing those inequalities occur, diversity networks are tamed and their value for equality will remain limited.

\section{Limitations, future research and practical implications}

When it comes to the limitations of this study, one limitation concerns the sample selection of the 
interviewees. We focused on board members as the shapers and drivers of diversity network goals and activities. Yet, regular members of the diversity networks may have other attitudes towards the activities and outcomes at the individual, group and organizational levels. Future studies could include a broader range of members and non-members to sketch a fuller picture of the tensions and contradictions in the effects of the networks. A second limitation is the limited number of five networks in one organization. For a fuller comparative study of diversity networks, more organizations and more networks should be included.

Our three-level framework provides avenues for further research with regard to other diversity management practices. Despite the increasing attention paid to diversity management in organizations, our current knowledge about which practices are most effective in which organizational settings and contexts remains limited (Bendl et al., 2015; Nkomo and Hoobler, 2014). Our framework encourages a critical analysis that distinguishes between multiple levels of organizational equality, and allows us to go beyond effects on the numerical representation of marginalized employees.

A practical implication of this study is that simply establishing diversity networks in organizations does not suffice to bring about substantial change towards equality. Diversity networks can contribute to equality when they challenge inequalities in organizational processes, when minority cultures can be legitimate and visible within the organization, and when a wide array of individual career trajectories and unique contributions are valued. Moreover, diversity networks are diversity management practices that focus on one single identity category. Current studies on diversity management practices, such as diversity networks, fail to theorize the heterogeneity within these identity categories. Researchers and practitioners alike could benefit from taking an intersectionality approach (Crenshaw, 1989; Rodriguez et al., 2016), taking into account multiple intersecting identities and how this impacts diversity networks.

\section{References}

Acker, J. (2006). 'Inequality regimes gender, class, and race in organizations', Gender \& Society, 20, pp. 441-464.

Ahmed, S. and E. Swan (2006). 'Doing diversity', Policy Futures in Education, 4, pp. 96-100.

Alvesson, M. and S. Deetz (2000). Doing Critical Management Research. London: Sage.
Bagilhole, B. and J. Goode (2001). 'The contradiction of the myth of individual merit, and the reality of a patriarchal support system in academic careers: a feminist investigation', European Journal of Women's Studies, 8, pp. 161-180.

Bell, M. P., M. F. Özbilgin, T. A. Beauregard and O. Sürgevil (2011). 'Voice, silence, and diversity in 21 st century organizations: strategies for inclusion of gay, lesbian, bisexual, and transgender employees', Human Resource Management, 50, pp. 131-146.

Bendl, R., Bleijenbergh, I., Henttonen, E. and Mills, A. J. (2015). The Oxford Handbook of Diversity in Organizations. Oxford: Oxford University Press.

Benschop, Y. (2006). 'Of small steps and the longing for giant leaps: research on the intersection of sex and gender within work and organizations'. In A. M. Konrad, P. Prasad and J. K. Pringle (eds), Handbook of Workplace Diversity, pp. 273298. London: Sage.

Benschop, Y., C. Holgersson, M. van den Brink and A. Wahl (2015). 'Future challenges for practices of diversity management in organizations'. In R. Bendl, I. Bleijenbergh, E. Henttonen and A. Mills (eds), The Oxford Handbook of Diversity in Organizations, pp. 553-574. Oxford: Oxford University Press.

Bierema, L. L. (2005). 'Women's networks: a career development intervention or impediment?', Human Resource Development International, 8, pp. 207-224.

Borgatti, S. P. and P. C. Foster (2003). 'The network paradigm in organizational research: a review and typology', Journal of Management, 29, pp. 991-1013.

Briscoe, F. and S. Safford (2008). 'The Nixon-in-China effect: activism, imitation, and the institutionalization of contentious practices', Administrative Science Quarterly, 53, pp. 460-491.

Briscoe, F. and S. Safford (2010). 'Employee affinity groups: their evolution from social movement vehicles to employer strategies', Perspectives on Work, 14, pp. 42-45.

Burt, R. S. (1998). 'The gender of social capital', Rationality and Society, 10, pp. 5-46.

Colgan, F. (2016). 'LGBT company network groups in the UK: tackling opportunities and complexities in the workplace'. In T. Köllen (ed.), Sexual Orientation and Transgender Issues Organizations: Global Perspectives on LGBT Workforce Diversity, pp. 525-538. New York: Springer.

Colgan, F. and A. McKearney (2012). 'Visibility and voice in organisations: lesbian, gay, bisexual and transgendered employee networks', Equality, Diversity and Inclusion: An International Journal, 31, pp. 359-378.

Crenshaw, K. (1989). 'Demarginalizing the intersection of race and sex: a black feminist critique of antidiscrimination doctrine, feminist theory and antiracist politics', University of Chicago Legal Forum, pp. 139-167.

Cross, C. and C. Armstrong (2008). 'Understanding the role of networks in collective learning processes: the experiences of women', Advances in Developing Human Resources, 10, pp. 600-613.

Eisenhardt, K. M. and M. E. Graebner (2007). 'Theory building from cases: opportunities and challenges', Academy of Management Journal, 50, pp. 25-32.

Ely, R. J. and D. E. Meyerson (2000a). 'Advancing gender equity in organizations: the challenge and importance of maintaining a gender narrative', Organization, 7, pp. 589-608.

Ely, R. J. and D. E. Meyerson (2000b). 'Theories of gender in organizations: a new approach to organizational analysis and change', Research in Organizational Behavior, 22, pp. 103-151. 
Foldy, E. (2002). 'Managing diversity: power and identity in organizations'. In I. Aaltio and A. J. Mills (eds), Gender, identity and the culture of organizations, pp. 92-112. London: Routledge.

Forret, M. L. and T. W. Dougherty (2004). 'Networking behaviors and career outcomes: differences for men and women?', Journal of Organizational Behavior, 25, pp. 419-437.

Friedman, R. A. (1996). 'Defining the scope and logic of minority and female network groups: can separation enhance integration?', Research in Personnel and Human Resources Management, 14, pp. 307-350.

Friedman, R. A. (1999). 'Employee network groups; self-help strategy for women and minorities', Performance Improvement Quarterly, 12, pp. 148-163.

Friedman, R. A. and K. M. Craig (2004). 'Predicting joining and participating in minority employee network groups', Industrial Relations: A Journal of Economy and Society, 43, pp. 793-816.

Friedman, R. A. and B. Holtom (2002). 'The effects of network groups on minority employee turnover intentions', Human Resource Management, 41, pp. 405-421.

Friedman, R. A., M. Kane and D. B. Cornfield (1998). 'Social support and career optimism: examining the effectiveness of network groups among black managers', Human Relations, 51, pp. 1155-1177.

Ghorashi, H. and I. Sabelis (2013). 'Juggling difference and sameness: rethinking strategies for diversity in organizations', Scandinavian Journal of Management, 29, pp. 78-86.

Githens, R. P. and S. R. Aragon (2009). 'LGBT employee groups: goals and organizational structures', Advances in Developing Human Resources, 11, pp. 121-135.

Granovetter, M. S. (1973). 'The strength of weak ties', American Journal of Sociology, 78, pp. 1360-1380.

Gremmen, I. and Y. Benschop (2011). 'Negotiating ambivalence: the leadership of professional women's networks'. In P. H. Werhane and M. Painter-Morland (eds), Leadership, Gender, and Organization, pp. 169-183. New York: Springer.

Gremmen, I. and Y. Benschop (2013). 'Vrouwennetwerken als diversiteitsinstrument in organisaties', Tijdschrift voor HRM, 3, pp. $32-54$.

Gusmano, B. (2010). 'Forms of resistance to the organization's symbolic heteronormative order'. In G. Clarke, F. McQueen, M. Pnacekova and S. Sahli (eds), Examining Aspects of Sexualities and the Self, pp. 31-43. Oxford: Inter-Disciplinary Press.

Hoobler, J. M. (2005). 'Lip service to multiculturalism: docile bodies of the modern organization', Journal of Management Inquiry, 14, pp. 49-56.

Ibarra, H. (1997). 'Paving an alternative route: gender differences in managerial networks', Social Psychology Quarterly, 60, pp. 91-102.

Janssens, M. and P. Zanoni (2014). 'Alternative diversity management: organizational practices fostering ethnic equality at work', Scandinavian Journal of Management, 30, pp. 317331.

Kalev, A., F. Dobbin and E. Kelly (2006). 'Best practices or best guesses? Assessing the efficacy of corporate affirmative action and diversity policies', American Sociological Review, 71, pp. 589-617.

Kaplan, M. M., E. Sabin and S. Smaller-Swift (2009). The Catalyst Guide to Employee Resource Groups. New York: Catalyst.

Kärreman, D. and M. Alvesson (2009). 'Resisting resistance: counter-resistance, consent and compliance in a consultancy firm', Human Relations, 62, pp. 1115-1144.
Kelan, E. K. (2014). 'From biological clocks to unspeakable inequalities: the intersectional positioning of young professionals', British Journal of Management, 25, pp. 790-804.

Kilduff, M. and D. J. Brass (2010). 'Organizational social network research: core ideas and key debates', Academy of Management Annals, 4, pp. 317-357.

Kolb, D., J. K. Fletcher, D. Meyerson, D. Merrill-Sands and R. J. Ely (1998). 'Making change: a framework for promoting gender equity in organizations', $C G O$ Insights, pp. 1-4.

Konrad, A. M. (2007). 'The effectiveness of human resource management practices for promoting women's careers'. In D. Bilimoria and S. K. Piderit (eds), Handbook on Women in Business and Management, pp. 254-276. Cheltenham: Edward Elgar Publishing.

Lorbiecki, A. and G. Jack (2000). 'Critical turns in the evolution of diversity management', British Journal of Management, 11, pp. s17-s31.

McDonald, S. (2011). 'What's in the "old boys" network? Accessing social capital in gendered and racialized networks', Social Networks, 33, pp. 317-330.

McFadden, C. and M. Crowley-Henry (2017). "My people": the potential of LGBT employee networks in reducing stigmatization and providing voice', The International Journal of Human Resource Management, https://doi.org/10.1080/09585192.2017.1335339.

Mehra, A., M. Kilduff and D. J. Brass (1998). 'At the margins: a distinctiveness approach to the social identity and social networks of underrepresented groups', Academy of Management Journal, 41, pp. 441-452.

Meyerson, D. E. and J. K. Fletcher (2000). 'A modest manifesto for shattering the glass ceiling', Harvard Business Review, 78, pp. $126-136$.

Meyerson, D. E. and D. M. Kolb (2000). "'Moving out of the armchair": developing a framework to bridge the gap between feminist theory and practice', Organization, 7, pp. 553-571.

Mor Barak, M. E. (2015). 'Inclusion is the key to diversity management, but what is inclusion?', Human Service Organizations: Management, Leadership \& Governance, 39, pp. 83-88.

Mor Barak, M. E. and D. A. Cherin (1998). 'A tool to expand organizational understanding of workforce diversity: exploring a measure of inclusion-exclusion', Administration in Social Work, 22, pp. 47-64.

Nahapiet, J. and S. Ghoshal (1998). 'Social capital, intellectual capital, and the organizational advantages', The Academy of Management Review, 23, pp. 242-266.

Nkomo, S. and J. M. Hoobler (2014). 'A historical perspective on diversity ideologies in the United States: reflections on human resource management research and practice', Human Resource Management Review, 24, pp. 245-257.

O'Neil, D. A., M. M. Hopkins and S. E. Sullivan (2011). 'Do women's networks help advance women's careers?: differences in perceptions of female workers and top leadership', Career Development International, 16, pp. 733-754.

Oswick, C. and M. Noon (2014). 'Discourses of diversity, equality and inclusion: trenchant formulations or transient fashions?', British Journal of Management, 25, pp. 23-39.

Phillips, N. and C. Hardy (2002). Discourse Analysis: Investigating Processes of Social Construction. Thousand Oaks, CA: Sage.

Pini, B., K. Brown and C. Ryan (2004). 'Women-only networks as a strategy for change? A case study from local government', Women in Management Review, 19, pp. 286-292. 
Potter, J. and M. Wetherell (1994). 'Analyzing discourse'. In A. Brynan and R. G. Burguss (eds), Analyzing Qualitative Data, pp. 47-66. London: Routledge.

Prasad, P. and A. J. Mills (1997). 'From showcase to shadow: understanding the dilemmas of managing workplace diversity'. In P. Prasad, A. J. Mills, M. Elmes and A. Prasad (eds), Managing the Organizational Melting Pot: Dilemmas of Workplace Diversity, pp. 3-27. London: Sage.

Roberson, Q. M. (2006). 'Disentangling the meanings of diversity and inclusion in organizations', Group \& Organization Management, 31, pp. 212-236.

Rodriguez, J. K., E. Holvino, J. K. Fletcher and S. M. Nkomo (2016). 'The theory and praxis of intersectionality in work and organisations: where do we go from here?', Gender, Work \& Organization, 23, pp. 201-222.

Rothstein, M. G., R. J. Burke and J. M. Bristor (2001). 'Structural characteristics and support benefits in the interpersonal networks of women and men in management', The International Journal of Organizational Analysis, 9, pp. 4-25.

Shore, L. M., A. E. Randel, B. G. Chung, M. A. Dean, K. H. Ehrhart and G. Singh (2011). 'Inclusion and diversity in work groups: a review and model for future research', Journal of Management, 37, pp. 1262-1289.

Siebers, H. (2010). 'The impact of migrant-hostile discourse in the media and politics on racioethnic closure in career development in the Netherlands', International Sociology, 25, pp. 475-500.

Silverman, D. (2006). Interpreting Qualitative Data: Methods for Analyzing Talk, Text, and Interaction. London: Sage.

Tatli, A. (2011). 'A multi-layered exploration of the diversity management field: diversity discourses, practices and practitioners in the UK', British Journal of Management, 22, pp. 238253.

Tomlinson, F. (1987). 'What do women's groups offer?', Women in Management Review, 2, pp. 238-247.

Vinnicombe, S., V. Singh and S. Kumra (2004). 'Making good connections: best practice for women's corporate networks', Cranfield University School of Management.

Yin, R. K. (2009). Case Study Research: Design and Methods. London: Sage.

Zanoni, P., M. Janssens, Y. Benschop and S. M. Nkomo (2010). 'Unpacking diversity, grasping inequality: rethinking difference through critical perspectives', Organization, 17, pp. 9-29.

Marjolein Dennissen is a PhD candidate at the Institute for Management Research at the Radboud University. She holds a Master's degree in Cultural Psychology from the same university and a Master's degree in Organization Studies from Tilburg University, the Netherlands. Her main research interests are in the field of critical diversity studies, with a particular focus on intersectionality and diversity networks in organizations. Past research projects include the European FP 7 GARCIA project and discursive practices of migrants' exclusion in the Netherlands.

Yvonne Benschop is Professor of Organizational Behaviour at the Institute for Management Research, Radboud University, the Netherlands. She is Head of the Department of Business Administration and director of the interdisciplinary research group Gender and Power in Politics and Management. She studies informal organization processes that produce organizational inequalities and interventions to change these processes and inequalities. She is currently working on a research project on the influence of postfeminism in organizational change.

Marieke van den Brink is Professor of Gender \& Diversity at the Institute of Social Cultural Research, Radboud University, the Netherlands and director of Radboud Gender \& Diversity Studies. She is a member of the Young Academy of the Royal Netherlands Academy of Arts and Sciences. The central themes of her research and teaching are gender and diversity in organizations, organizational learning and change, power and resistance, and she links these themes with macro developments such as migration, new public management and austerity.

\section{Supporting Information}

Additional supporting information may be found online in the Supporting Information section at the end of the article.

Appendix A1: Overview respondents.

Appendix A2: Interview guide.

Appendix A3: Illustrative data of discourses by diversity network board members.

Appendix A4: Overview of characteristics of the diversity networks in our study.

(c) 2018 The Authors. British Journal of Management published by John Wiley \& Sons Ltd on behalf of British Academy of Management. 